\title{
An investigation of the reasons for and expectations from boxing participation of male athletes who participated in the school sports young adults $b$ category boxing turkey championship
}

\author{
Metin YAMAN, Hüseyin ÇİÇEK \\ Gazi University, Faculty of Sports Sciences, Ankara, Turkey \\ Address Correspondence to , e-mail: cicekhuseyn@hotmail.com
}

\begin{abstract}
The present study aims to investigate the reasons for and expectations from boxing participation of male athletes who participated in the 2018 School Sports Young Adults B Category Boxing Turkey Championship held in Erzincan. Method: The present study enrolled the licensed athletes who participated in the 2018 School Sports Young Adults B Category Boxing Turkey Championship. A total of 150 athletes participated in this Championship. It was conducted with the voluntary participation of the male athletes participating in the Turkey Finals of the School Sports Young Adults B Category. The population of the study consists of 150 athletes, and the sample consists of 102 male athletes. Personal information form developed by Ayilgan (2017) was used to collect the data. The data were analysed by frequency distribution and percentage distribution in SPSS 17.0 package program. Findings: Of the participants, $2 \%$ were in the $10-14$ age range while $98 \%$ were in the $15-19$ age range. Besides, $33.3 \%$ of the participants reside in metropolises, $51.0 \%$ in cities and $15.7 \%$ in districts. It was also found that $31.4 \%$ of the participants were engaged in boxing for one year, $18.6 \%$ for two years, $18.6 \%$ for three years, $15.7 \%$ for four years, and $15.7 \%$ for five years and more. A majority (52\%) of the participants planned to be national athletes in the future and received sufficient support from their social circles. $47 \%$ of the participants received rewards or bonuses from their clubs whereas $53 \%$ received no awards or bonuses. Conclusion: Considering the responses of the athletes who participated in our study, it can be seen that they are fond of boxing and their social circles have sufficient knowledge of boxing.
\end{abstract}

Key words: Boxing, Participation, Expectation, Sports.

\section{INTRODUCTION}

Sport is a tool that provides physical, mental, emotional and social development of individuals and enhances their knowledge, skills and leadership abilities. Sport helps one to discipline himself and to overcome psychological and physiological problems. Sports enable international friendship and peace and provide positive benefits to the countries' economy. In addition, nowadays, both the media's approach to sports and the efforts of people to get rid of stress and keep their bodies in shape and above all, the success of national athletes in international sports events have given sport an important place in the daily life of people $(1,3)$.

Boxing, one of the oldest sports in the world, has been described in various ways by sports scientists. Some of these are as follows: A sport known as fighting, attacking, defending or reciprocal fighting based on the fist fighting of two people wearing special gloves following certain rules (13). Boxing is a struggle of two athletes in a square-shaped area surrounded by three rows of rope (ring) in the framework of certain rules by wearing specially produced gloves (16). Boxing is a sports branch where two people are wearing special gloves hit each other with their fists by the rules (8). Boxing is a sport between two people using their fists within a certain time (round), in a certain area (ring), and by certain rules (15). Boxing has a complex structure due to the highest dynamic and static properties. It is also among the combat sports that require a maximum force (11).

Boxing is one of the sports branches that require physical contact and struggle. Boxing training develops aerobic and anaerobic power and provides maximal improvements in flexibility and reflexes (5). 
Boxing is a sport that has to be done according to certain rules. If we examine this fact in terms of defence and attack based contact sports, we can better understand the reasons. When the rules are applied with rigidity and precision, sports activity takes a standard dimension (14).

Up to date, studies have been conducted investigating the reasons for and expectations from participation in sports of athletes and students in different fields; however, no studies have been conducted on this with students in sports schools. It is the primary purpose of this study to identify the main reasons why these individuals start sports and why they choose a certain sports branch, and to investigate the future expectations of these individuals.

\section{MATERİAL AND METHOD}

Conducted to investigate the reasons for and expectations of the athletes who participated in the 2018 School Sports Young Adults B Category Boxing Turkey Championship, the present study utilised relational (survey) model.

The universe and sample of the research The universe of the research consists of a total of 102 licensed male athletes who participated in the 2018 School Sports Young Adults B Category Boxing Turkey Championship, and who participated in regional, national and international competitions.

Personal information form developed by Ayilgan (2017) was used to collect the data. The data collection tool consists of three parts including personal information. The first part, the personal information part contains ten demographic questions. In the second part, the athletes were asked ten questions about the environmental factors affecting them. The data were evaluated and interpreted using appropriate statistical methods.

In the study, frequency distribution and percentage distribution of SPSS 17.0 Package Program were used as test statistics, and demographic information and expectation levels of the participants were examined.

\section{INTERPRETATION OF ANALYSIS AND} FINDINGS

\begin{tabular}{lll}
\hline \multicolumn{3}{l}{ Table 1. Distribution of residences of the participants } \\
\hline Place of Residence & $\mathrm{F}$ & $\%$ \\
\hline Metropolis & 34 & 33.3 \\
\hline City & 52 & 51.0 \\
\hline District & 16 & 15.7 \\
\hline Total & 102 & 100 \\
\hline
\end{tabular}

Table 1. Of the athletes who participated in the study, 33.3\% live in metropolises, $51 \%$ in cities, and $15.7 \%$ in districts.

Table 2. Distribution of occupations of the fathers of the participants

\begin{tabular}{lll}
\hline $\begin{array}{l}\text { Occupations of the } \\
\text { Fathers }\end{array}$ & $\mathrm{F}$ & $\%$ \\
\hline Civil Servant & 22 & 21.6 \\
\hline Worker & 30 & 29.4 \\
\hline Self-employed & 36 & 35.3 \\
\hline Farmer & 3 & 2.9 \\
\hline Retired & 10 & 9.8 \\
\hline Unemployed & 1 & 1.0 \\
\hline Total & 102 & 100 \\
\hline
\end{tabular}

Table 2. Of the fathers of the athletes, $21.6 \%$ are civil servants, $29.4 \%$ are workers, $35.3 \%$ are selfemployed, $2.9 \%$ are farmers, $9.8 \%$ are retired, and $1 \%$ is unemployed.

Table 3. Distribution of occupations of the mothers of the participants

\begin{tabular}{lll}
\hline Occupations of the Mothers & F & $\%$ \\
\hline Civil Servant & 8 & 7.8 \\
\hline Worker & 9 & 8.8 \\
\hline Self-employed & 6 & 5.9 \\
\hline Retired & 18 & 17.6 \\
\hline Unemployed-Housewife & 61 & 59.8 \\
\hline Total & 102 & 100 \\
\hline
\end{tabular}

Table 3. Of the mothers of the athletes, $7.8 \%$ are civil servants, $8.8 \%$ are workers, $5.9 \%$ are selfemployed, $17.6 \%$ are retired, and $59.8 \%$ are unemployed/housewives. 
Table 4. Distribution of the monthly income levels of the parents of the participants

\begin{tabular}{lll}
\hline Monthly income & F & $\%$ \\
\hline$<500$ & 3 & 2.9 \\
\hline $501-1000$ & 7 & 6.9 \\
\hline $1001-1500$ & 15 & 14.7 \\
\hline $1501-2000$ & 30 & 29.4 \\
\hline 2001 and above & 47 & 46.1 \\
\hline Total & 102 & 100 \\
\hline
\end{tabular}

Table 4. Of the parents of the athletes, $2.9 \%$ have a monthly income level of $<500 \mathrm{TL}, 6.9 \%$ 501-1000 $\mathrm{TL}, 14.7 \%$ 1001-1500 TL, $29.4 \%$ 1501-2000 TL, and $46.1 \% 2001 \mathrm{TL}$ and above.

Table 5. Distribution of how many years the participants have been doing this sport

How many years the

$\mathrm{F} \quad \%$

participants have been doing

this sports

\begin{tabular}{lll}
\hline 1 & 32 & 31.4 \\
\hline 2 & 19 & 18.6 \\
\hline 3 & 19 & 18.6 \\
\hline 4 & 16 & 15.7 \\
\hline 5 and more & 16 & 15.7 \\
\hline Total & 102 & 100 \\
\hline
\end{tabular}

Table 5. Of the athletes, $31.4 \%$ have been doing this sport for one year, $18.6 \%$ for two years, $18.6 \%$ for three years, $15.7 \%$ for four years, and $15.7 \%$ for five years and more.

Table 6 . Of the athletes, $2 \%$ train one day a week, $7.8 \%$ two days a week, $25.5 \%$ three days a week, $24.5 \%$ four days a week, and $40.2 \%$ five days a week.

Table 7. Distribution of the hours the participants train

\begin{tabular}{lll}
\hline $\begin{array}{l}\text { The hours the participants } \\
\text { train a day }\end{array}$ & $\mathrm{F}$ & $\%$ \\
\hline 1 hour & 9 & 8.8 \\
\hline 1.5 hour & 76 & 74.5 \\
\hline 2 hours and more & 17 & 16.7 \\
\hline Total & 102 & 100 \\
\hline
\end{tabular}

Table 7. Of the participants, $8.8 \%$ train one hour a day, $74.5 \% 1.5$ hours, and $16.7 \% 2$ hours and more.
Table 6. Distribution of the number of weekly training sessions

\begin{tabular}{|c|c|c|}
\hline $\begin{array}{l}\text { The number of } \\
\text { training sessions }\end{array}$ & $\mathrm{F}$ & $\%$ \\
\hline One day & 2 & 2.0 \\
\hline Two days & 8 & 7.8 \\
\hline Three days & 26 & 25.5 \\
\hline Four days & 25 & 24.5 \\
\hline Five days & 41 & 40.2 \\
\hline Total & 102 & 100 \\
\hline
\end{tabular}

Table 8. Distribution of the opportunities provided by the clubs

\begin{tabular}{lll}
\hline $\begin{array}{l}\text { Opportunities provided by } \\
\text { the clubs }\end{array}$ & $\mathrm{F}$ & $\%$ \\
\hline Social Security & 11 & 10.8 \\
\hline Health Guarantee & 25 & 24.5 \\
\hline Employment Guarantee & 13 & 12.7 \\
\hline Economic Earnings & 5 & 4.9 \\
\hline Equipment & 38 & 37.3 \\
\hline Shelter & 4 & 3.9 \\
\hline None & 6 & 5.9 \\
\hline Total & 102 & 100 \\
\hline
\end{tabular}

Table 8 . Of the clubs of the athletes, $10.8 \%$ provide social security for the participants, $24.5 \%$ health guarantee, $12.7 \%$ employment guarantee, $4.9 \%$ economic earnings, $37.3 \%$ equipment, $3.9 \%$ shelter, and $5.9 \%$ provide none of these.

\begin{tabular}{l} 
Table 9. Distribution of whether the participants \\
receive any rewards or bonuses from their clubs \\
\hline $\begin{array}{l}\text { Whether the clubs give } \\
\text { rewards or bonuses }\end{array}$
\end{tabular}

Table 9. Of the athletes, $46.1 \%$ receive rewards or bonuses whereas $53.9 \%$ do not receive any rewards or bonuses.

Table 10. Distribution of whether the participants are provided with sufficient facilities

\begin{tabular}{lll}
\hline Are the facilities sufficient? & F & $\%$ \\
\hline Yes & 66 & 64.7 \\
No & 36 & 35.3 \\
Total & 102 & 100 \\
\hline
\end{tabular}


Table 10 . Of the participants, $64.7 \%$ are provided with sufficient facilities whereas $35.3 \%$ are not.

Table 11. Distribution of plans of the

participants

\begin{tabular}{lll}
\hline Future Plans & F & $\%$ \\
\hline Academic Training & 10 & 9.8 \\
\hline Continue at the Club & 5 & 4.9 \\
\hline Be a Coach & 26 & 25.5 \\
\hline Be a Manager & 3 & 2.9 \\
\hline Be a National Athlete & 56 & 54.9 \\
\hline No Plans & 2 & 2.0 \\
\hline Total & 102 & 100 \\
\hline
\end{tabular}

Table 11. Of the participants, $9.8 \%$ plan to receive academic training in the future, $4.9 \%$ plan to continue at the club, $25.5 \%$ plan to be a coach, $2.9 \%$ plan to be a manager, $54.9 \%$ plan to be a national athlete, and $2 \%$ have no plans.

Table 12. Distribution of whether the participants receive sufficient support from their social circles

\begin{tabular}{lll}
\hline Yes & 71 & 69.6 \\
\hline No & 31 & 30.4 \\
\hline Total & 102 & 100 \\
\hline
\end{tabular}

Table 12. Of the athletes, $69.6 \%$ stated that they receive sufficient support from their social circles whereas 30.4 stated that they do not.

Table 13. Distribution of whether the participants believe their social circles have sufficient knowledge of boxing

\begin{tabular}{lll}
\hline $\begin{array}{l}\text { Do you believe your social } \\
\text { circle has sufficient knowledge } \\
\text { of boxing? }\end{array}$ & F & $\%$ \\
\hline Yes & 79 & 77.5 \\
\hline No & 23 & 22.5 \\
\hline Total & 102 & 100 \\
\hline
\end{tabular}

Table 13. Of the participants, $77.5 \%$ believe that their social circles have sufficient knowledge of boxing whereas $22.5 \%$ do not believe so.

\section{CONCLUSION AND EVALUATION}

Every individual is born as a part of society. The beliefs, lives, tastes and choices of individuals are shaped by the society to which they belong. The cultures of societies are shaped by the traditions and customs from the past to the present, religious beliefs, and geographic region. Similar situations can be observed in the selection of sports branches. By determining the socio-economic and demographic characteristics of the male athletes participating in the selected branch (Boxing), the present study aims to increase the levels of participation in such branches and to make a more positive contribution to the expectations (9).
When we look at the residences of the participants, $33.3 \%$ live in metropolises, $51 \%$ in cities, and $15.7 \%$ in districts. Devecioglu and Sarikaya (2004) reported that $62.5 \%$ of students engaged in sports reside in city centers. This finding indicates that this branch is preferred in all three different places. Most of the athletes participating in our study live in cities and metropolitan areas. The reasons for this are the excess of facilities in the cities (sports halls, sports clubs, coaches, etc.). When we examine whether the participants are provided with sufficient facilities, $63.7 \%$ stated that they have sufficient facilities whereas $35.3 \%$ stated they do not. This finding indicates that most of the participants believe that they have sufficient facilities. The presence of suitable fields, facilities and materials can be the determining factors for the participants to choose a sports branch. A study conducted in 2008 in Canada reported that children away from playgrounds or parks are less engaged in sports than those close to playgrounds or parks (12).

Of the fathers of the athletes, $21.6 \%$ are civil servants, $29.4 \%$ are workers, $35.3 \%$ are selfemployed, $2.9 \%$ are farmers, $9.8 \%$ are retired, and $1 \%$ are unemployed. This finding indicates that a majority of the fathers of the participants are selfemployed. Of the mothers of the athletes, $7.8 \%$ are civil servants, $8.8 \%$ are workers, $5.9 \%$ are selfemployed, $17.6 \%$ are retired, and $59.8 \%$ are unemployed/housewives. Similarly, in a study by Ayilgan, $62.8 \%$ of the mothers of the participants were unemployed or housewives. This finding is consistent with the finding of our study. This finding also indicates that a majority of the mothers of the participants are either unemployed or housewives.

Of the parents of the athletes, $2.9 \%$ have a monthly income level of $<500 \mathrm{TL}, 6.9 \% 501-1000 \mathrm{TL}, 14.7 \%$ 1001-1500 TL, 29.4\% 1501-2000 TL, and 46.1\% 2001 $\mathrm{TL}$ and above. This finding indicates that the parents of the participants had a monthly income level that is close to the minimum wage.

Of the athletes, $31.4 \%$ have been doing this sport for one year, $18.6 \%$ for two years, $18.6 \%$ for three years, $15.7 \%$ for four years, and $15.7 \%$ for five years and more. In the study by Ayilgan (2017), $32.7 \%$ of the participants were engaged in boxing for 1-2 years, which is consistent with the finding obtained in this study. This finding indicates that $15.7 \%$ of the participants have been engaged in boxing for 5 or more years. Of the athletes, $2 \%$ train 
one day a week, $7.8 \%$ two days a week, $25.5 \%$ three days a week, $24.5 \%$ four days a week, and $40.2 \%$ five days a week. In the study by Ayilgan (2017), 64.5\% of the participants trained five days or more a week. This finding indicates that most of the participants train 3 or 4 days a week. Of the athletes, $8.8 \%$ train 1 hour a day, $74.5 \% 1.5$ hours, and $16.7 \% 2$ hours and more. This finding indicates that most of the participants who participated in the championship preferred training 2 hours a day at most. Of the clubs of the athletes, $10.8 \%$ provide social security for the participants, $24.5 \%$ health guarantee, $12.7 \%$ employment guarantee, $4.9 \%$ economic earnings, $37.3 \%$ equipment, $3.9 \%$ shelter, and $5.9 \%$ provide none of these. In the study by Ayilgan (2017), 28.7\% of the clubs provided no opportunities for the participants. This finding indicates that clubs mostly provide equipment for the participants. Of the athletes, $46.1 \%$ receive rewards or bonuses whereas $53.9 \%$ do not receive any rewards or bonuses. In the study by Ayilgan (2017), 59.7\% of the participants received no rewards or bonuses from their clubs.

Of the athletes, $9.8 \%$ plan to receive academic training in the future, $4.9 \%$ plan to continue at the club, $25.5 \%$ plan to be a coach, $2.9 \%$ plan to be a manager, $54.9 \%$ plan to be a national athlete, and $2 \%$ have no plans. It can be seen that a majority of the athletes want to be national athletes in the future. Being a national athlete and being selected for the national team is very important for the sports career of the athlete and his expectations from the sports he does (7).

Of the athletes, $69.6 \%$ stated that they receive sufficient support from their social circles whereas 30.4 stated that they do not. This finding indicates that most of the athletes receive support from their social circles. Of the participants, $77.5 \%$ believe that their social circles have sufficient knowledge of boxing whereas $22.5 \%$ do not believe so. This finding indicates that most people in the social circles of the participants have sufficient knowledge of boxing.

From this result, we can conclude that the participants are fond of being engaged in boxing and that they believe that their social circles have sufficient knowledge of boxing. M. Kumartasli and E.Atabasin (2014) reported that individuals are fond of doing the sports that they do. Demanding sports such as boxing requires ultimate motivation and sacrifice.
In conclusion, the athletes engaged in boxing have poor socio-economic conditions and low incomes, their parents are mostly self-employed, or housewives and most of the participants are primary school graduates. We can argue that despite their poor socio-economic conditions and low incomes, poor educational background, and unfavourable conditions, the participants want to be national athletes and increase the quality of their lives. Furthermore, we have found that most of the participants, unfortunately, did not receive any rewards or bonuses from their clubs. For this reason, the conditions of the athletes need to be improved, and the athletes need motivation.

Future research may be conducted on the reasons for engagement in other sports branches.

\section{REFERENCES}

1. Acikada C, Ergen E, Science and Sports, Bureau Tek Offset Printing, Ankara, 1990, p: 5.

2. Ayilga E, An Investigation of Female Athletes' Reasons for and Expectations from Participation in Some Sports Branches (Wrestling, Weight Lifting, Taekwondo), Master Thesis, 2017.

3. Baser E, Practical Sports Psychology, MEGSB, General Directorate of Physical Education, Publication No: 31, Ankara, 1986, p: 28.

4. Birol PS, Socioeconomic Structures of Grass Hockey and Ice Hockey Athletes in Turkey, Investigation of Reasons for and Expectations from Participation in These Sports, Unpublished Master Thesis, Gazi University Institute of Educational Sciences, Ankara, 2007.

5. Cakmakci O, Comparison of Selected Physical Characteristics of Turkey and Georgia National Teams, Master Thesis, Konya, 2002, P.11.

6. Devecioglu S, Sarikaya M, Determining the Profiles of Sports Students in the Light of Socio-Economic Variables, Firat University Journal of Social Sciences, Elazig, 2004, 16 (2), 301314.

7. Dulger F, Socioeconomic Levels of Turkish Badminton Athletes, Master Thesis, Inonu University, Institute of Health Sciences, Malatya, 1998, 47-54.

8. Inan V, Boxing Without Being Punched, 1980.

9. Koca and Bulgun C, Sports and Gender: An Overview. Journal of Society and Science, 103, 2005, 163-184.

10. Kumartasli M, Atabas EG, "Evaluation of Expectations of Individuals Using Sports Center Fitness Halls," International Journal of Science Culture and Sport, 2014.

11. Mitchell JH, Haskell WAI, Raven PB, Classification Of Sports, Medicine And Science In Sports And Exercise, American College Of Sports Medicine And American College Of Cardiology, 1994, p: 242-244.

12. Saskatchewan Ministry of Tourism Parks, Culture And Sport, Mach, Factors That Shape Our Children's Participation in Physical Activity and Sports A Saskatchewan Parents Perspective, 2008, 11.

13. Savas I, Sports General Culture, Inkilap Publishing, Istanbul, 1998, p: 76-78. 
14. Sevim Y, Savas S., Talent Selection in Sport, Journal of Science and Technology, 1993, 785-788.

15. Sengul K, History of Boxing. Baskent Publishing House, 1991.

16. Varlik S, Boxing: Basic Training, 1982, p: 21, 22-118. 